KfK 2815

Juni 1979

\title{
Preparation of NbN Single Crystals
}

B. Scheerer Institut für Angewandte Kernphysik

\section{Kernforschungszentrum Karlsruhe}


KERNFORSCHUNGSZENTRUM KARLSRUHE

Institut für Angewandte Kernphysik

KfK 2815

Preparation of $\mathrm{NbN}$ Single Crystals

B. Scheerer

Kernforschungszentrum Karlsruhe GmbH., Karlsruhe 
Als Manuskript vervielfältigt

Für diesen Bericht behalten wir uns alle Rechte vor

Kernforschungszentrum Karlsruhe $\mathrm{GmbH}$

ISSN 0303-4003 


\section{$\underline{\text { Abstract }}$}

\section{Preparation of $\mathrm{NbN}$ Single Crystals}

NbN single crystals were prepared for measurements of the phonon dispersion by inelastic neutron scattering and as starting material for ion implantation experiments. Series of experiments have been done to study three different possibilities to get crystals of the required size. The crystals were characterized by chemical analysis, $\mathrm{x}$-ray- and neutron diffraction and also by determination of the superconducting transition temperature.

\section{$\underline{\text { Kurzfassung }}$}

\section{Herstellung von NoN Einkristallen}

Für Messungen der Phononendispersion an NbN mittels unelastischer Neutronenstreuung und als Ausgangsmaterial für Ionen-ImplantationsExperimente wurden NbN-Einkristalle hergestellt. In einer Reihe von Versuchen wurden drei verschiedene Möglichkeiten untersucht, um Kristalle entsprechender Größe zu erhalten. Die Kristalle wurden durch chemische Analyse, Röntgen- und Neutronendiffraktion und durch Messungen der supraleitenden sprungtemperatur charakterisiert. 


\section{Table of Contents}

Abstract

Ḱurzfassung

1. Introduction $\ldots \ldots \ldots \ldots \ldots \ldots \ldots \ldots \ldots \ldots \ldots \ldots \ldots \ldots \ldots \ldots \ldots$

2. Experimental Studies $\ldots \ldots \ldots \ldots \ldots \ldots \ldots \ldots \ldots \ldots \ldots$

3. Characterization $\ldots \ldots \ldots \ldots \ldots \ldots \ldots \ldots \ldots \ldots$

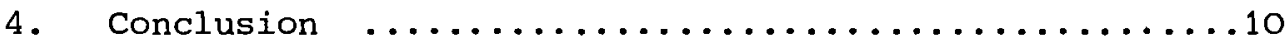

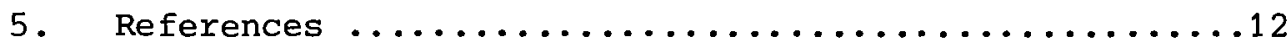

6. Appendix: Tables and Phase Diagram $\ldots \ldots \ldots \ldots \ldots \ldots 13$ 


\section{Introduction}

The monocarbides and mononitrides of the transition metals with $\mathrm{NaCl}$ structure have gained increasing interest because of their exceptional physical properties, such as extreme hardness and very high melting temperatures. Many representatives of this group are excellent superconductors with transition temperatures up to $18 \mathrm{~K}$. The mechanical and superconducting properties are very much a function of the nonmetal-to-metal ratio.

A considerable contribution to the understanding of the microscopic properties of these materials is made by the determination of the phonon state density and phonon dispersion. The phonon state density can be measured in polycristalline material, while single crystals with a volume of at least $0.1 \mathrm{~cm}^{3}$ are necessary to determine the phonon dispersion.

It has been possible for us so far to produce larger single crystals of carbides, such as $\mathrm{TiC} / 1 /$, vC $/ 2 /$ and $\mathrm{NbC} / 3,4 /$, by floating zone melting. In the meantime, measurements of the phonon dispersion have been carried out on these crystals /5, $6,7 /$.

Among the superconducting nitride compounds with $\mathrm{NaCl}$ structure niobium nitride attracts special interest because of its high transition temperature of $16.7 \mathrm{~K}$. This was first measured in 1941 by Justi and co-workers /8/ on specimens which had been obtained by diffusion of nitrogen into sintered niobium bodies at high temperatures.

Various authors have since reported about the preparation and superconducting properties of niobium nitride. Rögener /9/ obtained niobium nitride samples by diffusion of nitrogen in niobium wire. G. V. Samsonóv $/ 10 /, \mathrm{K}$. Hechler and $\mathrm{E}$. Saur $/ 11 /$ reported about the preparation and, specifically, the superconducting properties of pure niobium nitride and ternary niobium nitride compounds, and A. N. Christensen /12/ described the preparation of niobium nitride single crystals. Drafting a phase diagram of the $\mathrm{Nb}-\mathrm{N}$ system has since been the objective of studies, among others, by G. Brauer and H. Kirner /13/, R. W. Guard et al. /14/ and C. Politis /15/. 
Growing niobium nitride single crystals with NaCl structure turned out to be extremely difficult, because this phase can be produced only in a very narrow range of temperatures, pressures and concentrations (see phase diagram in the appendix, page 16). For this reason, it has not been possible so far to acquire larger niobium nitride single crystals for measurement purposes. For studies of the phonon dispersion in niobium nitride by inelastic neutron scattering we were compelled to start our own program of preparing suitable single crystals.

\section{Experimental Studies}

The possibilities at hand for the preparation of $\mathrm{NbN}$ single crystals were found in the following procedures:

(A) RF-zone melting of hot-pressed $\mathrm{NbN}$ powder rods under nitrogen atmospheres up to 20 bar overpressure.

(B) Nitriding a $\mathrm{Nb}$ single crystal in a nitrogen atmosphere with an overpressure of up to 100 bar. Heating by a graphite heating element.

(C) Nitriding a $\mathrm{Nb}$ single crystal in a nitrogen atmosphere with an overpressure up to 20 bar with RF heating.

\section{$\underline{2 . A}$}

These experiments were carried out in our single crystal drawing facility of the EKZ 300/100 type made by Leybold Heraeus /16/. The radio frequency (RF) generator installed, which was manufactured by Hüttinger $/ 17 /$, supplies a maximum power of approx. $40 \mathrm{~kW}$ in the specimen with a frequency of approx. $250 \mathrm{kHz}$. The system allows work to be performed under inert gas up to a maximum overpressure of 20 bar. The facility is shown in Fig. 1 . 


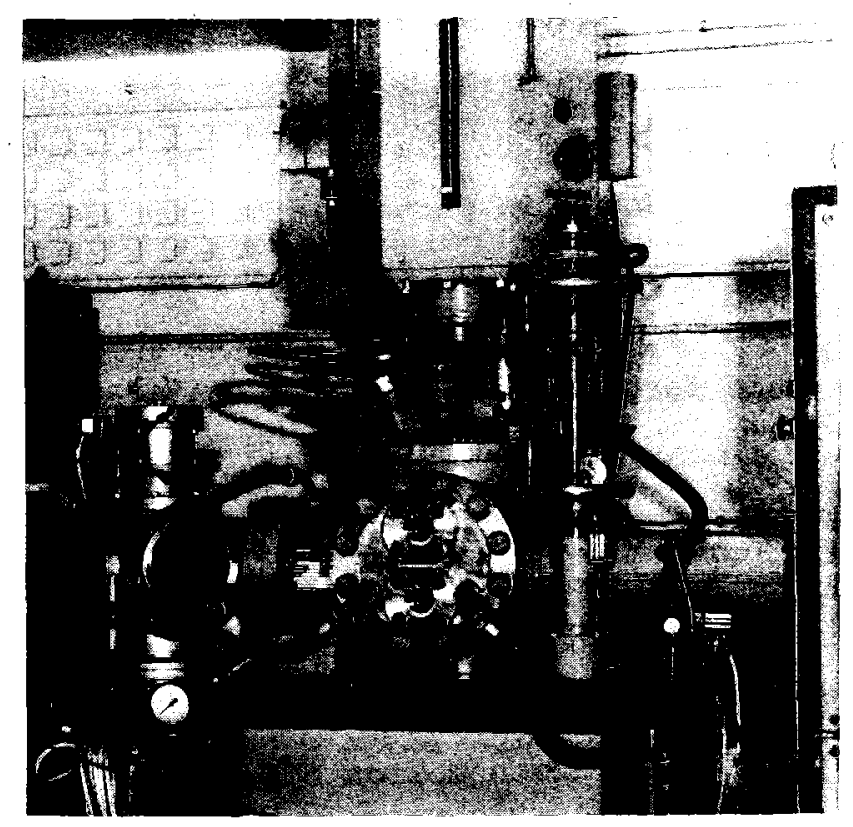

Fig. 1 Single crystal growth facility

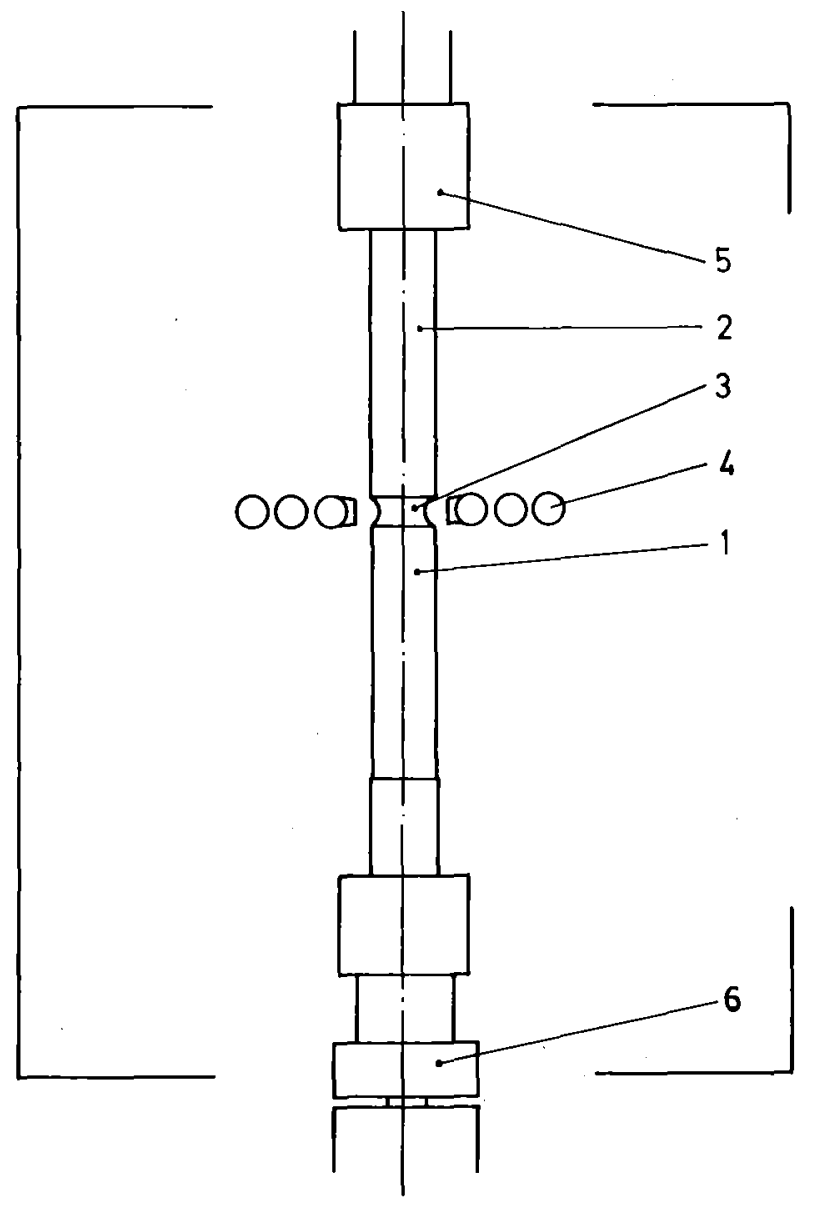

1 zone nolten rod

2 powder rod

3 molten zone

4 RF-coil

5 chuck

6 free-wheel

Fig. 2 The experimental facility in the recipient 
The source material was hot pressed $\mathrm{NbN}$ powder made by Cerac /18/ as rods with a diameter of approx. $12 \mathrm{~mm}$ and a length of approx. $150 \mathrm{~mm}$. Chemical analysis indicated that the nitrogen/niobium ratio in the rods varied within broad limits, between 0.68 and 0.84 (Table 1). The material was molten by floating zone drawing. For this purpose, the rod was clamped in a support on both ends and moved through the radio frequency coil vertically downward at a rate of $8 \mathrm{~mm} / \mathrm{h}$. The two drawing shafts rotated in opposite senses. This was made for good mixing of the melting zone, uniform heating of the surface and almost cylindrical growth. Fig. 2 shows the experimental facility inside the recipient. Specially designed RF-coils were necessary for induction heating of the material (Fig. 3). They achieved good melting behavior and melting zones as small as possible. It was possible in this way to zone the material over a length of up to $75 \mathrm{~mm}$. Fig. 4 shows a zone molten $\mathrm{NbN}_{1-\mathrm{x}}$ rod.

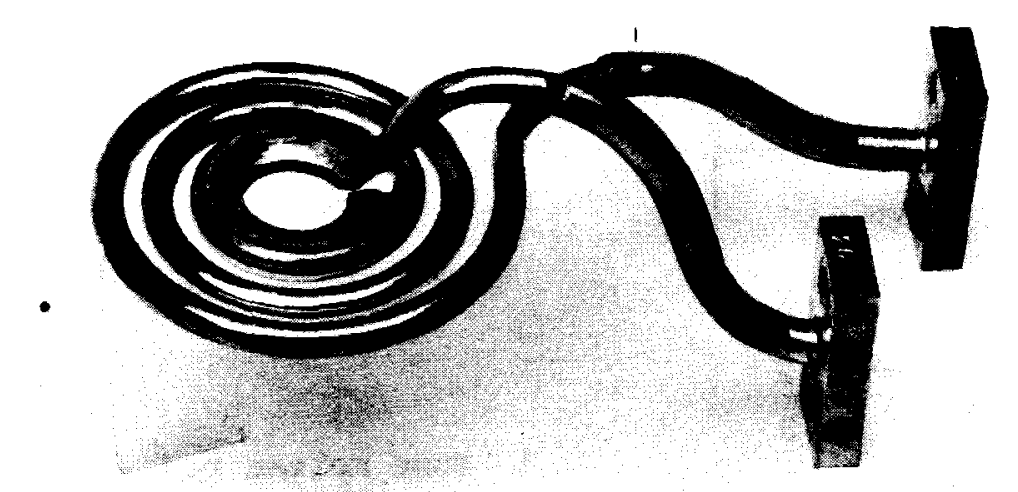

Fig. 3 RF-coil for Zone melting

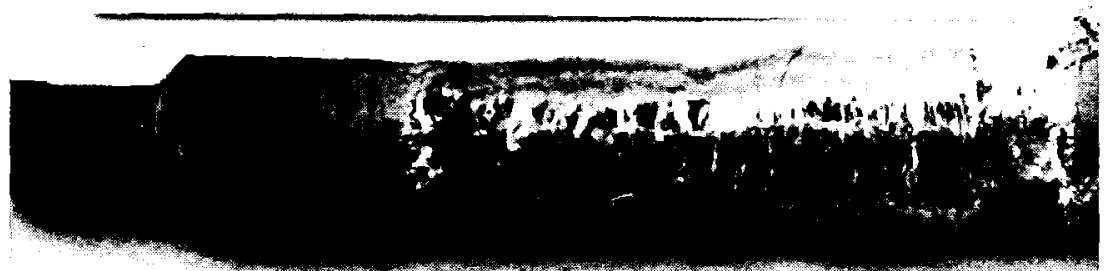

Fig. 4 Zone molten $\mathrm{NbN}_{1-\mathrm{x}} \operatorname{rod}$

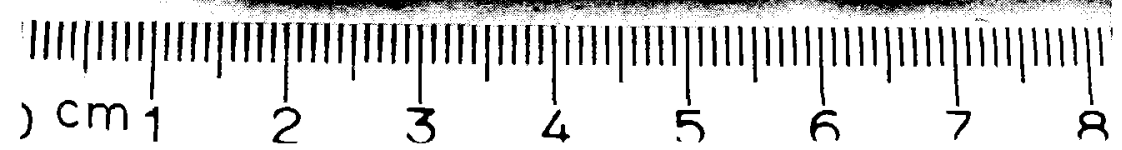


To diminish the considerable degasing which occurs at the melting point of $\mathrm{NbN} / 19 /$ and to reduce thereby the nitrogen loss, the experiments were performed under a nitrogen atmosphere at a maximum pressure of 20 bar.

For structural analysis the zoned rods were examined on a neutron diffractometer at the FR2 reactor in Karlsruhe.

The crystalline regions with volumes $>1 \mathrm{~cm}^{3}$ were cut of the zonedrawn rod (Fig. 5). Fig. 6 shows the cross section of a zoned niobium nitride rod. The lamellar multidomain structure is clearly seen which

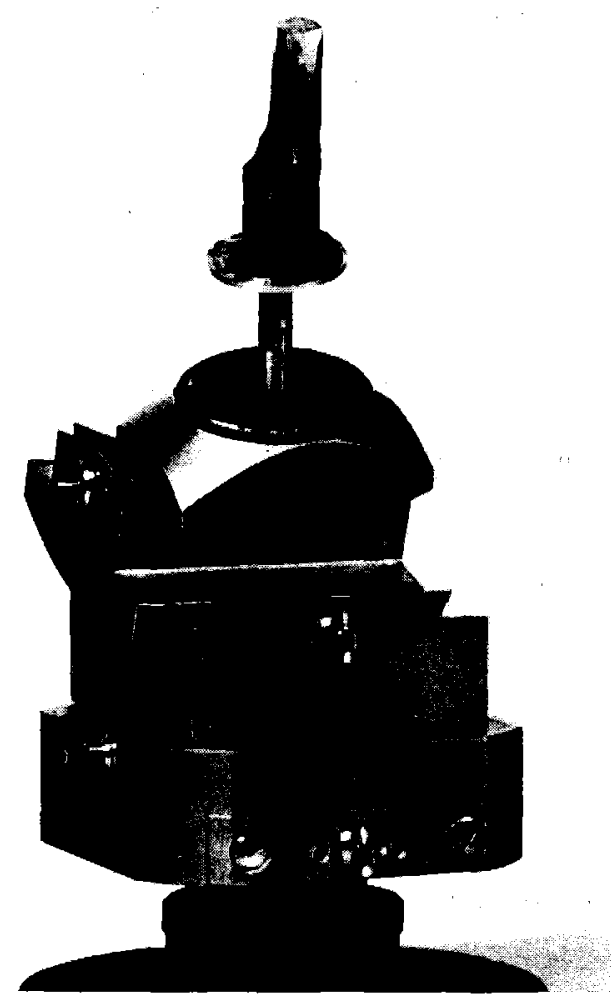

Fig. $5 \mathrm{NoN} .64$ sample

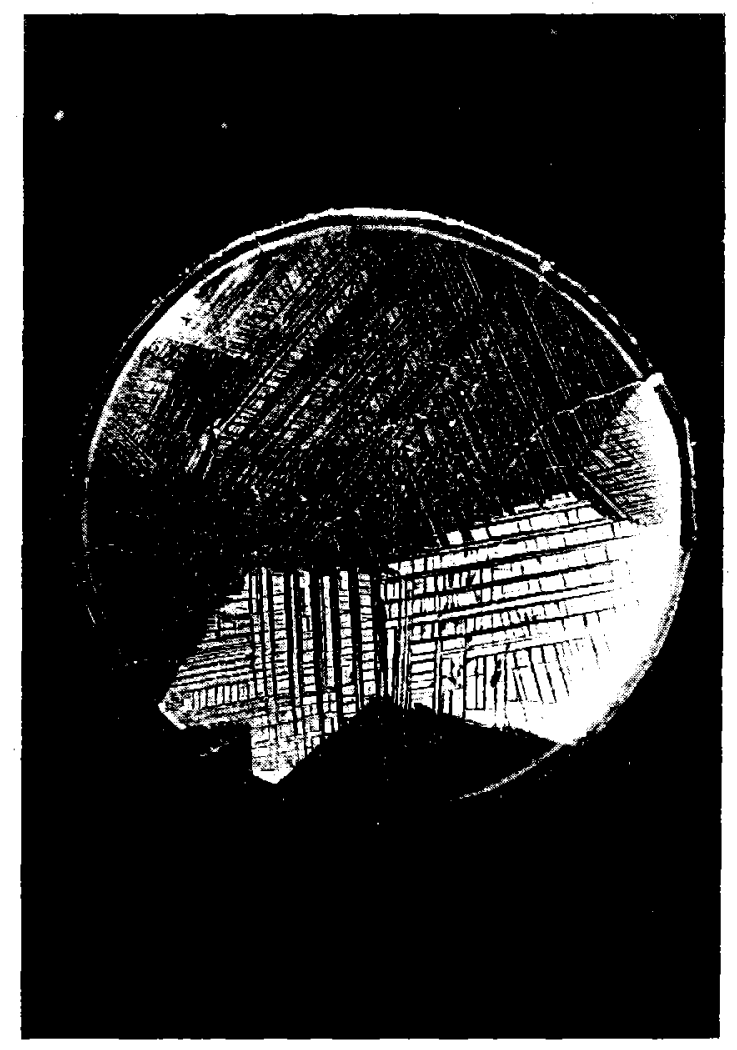

Fig. 6 Cross section of a zoned $\mathrm{NbN}_{1-\mathrm{x}} \operatorname{rod}$ 
results from the transition from the cubic $\delta-\mathrm{NbN}$ phase into the hexagonal + tetragonal $\beta+\beta-\mathrm{NbN}$ phase during cooling. Chemical analysis of the material indicated a $N / N b$ ratio of only 0.64 . From the phase diagram it is evident that a higher $\mathrm{N} / \mathrm{Nb}$ ratio was not to be expected because of the high equilibrium nitrogen gas pressure at the melting point of NoN. For this reason, this method of preparation was only able to prepare low-nitrogen multiphase, multidomain $\mathrm{NbN}_{1-\mathrm{x}}$ crystals.

Raising the nitrogen gas pressure in the recipient above the equilibrium nitrogen gas pressure of $\mathrm{NbN}$ at the melting point will probably lead to success. However, this is not possible in our facility $\left(\mathrm{P}_{\max }=20 \mathrm{bar}\right)$. In the cooling-process also the phase transformation from $\delta-\mathrm{NbN}$ into $\gamma+\varepsilon-\mathrm{NbN}$ must be taken into account. This transformation can be avoided by rapid cooling of the sample from above some $1400^{\circ} \mathrm{C}$. However, in zone melting a relatively slow cooling process occurs, corresponding to the rate of drawing, which gives more chances to induce a phase transformation.

\section{B}

For this reason, we continued our experiments using a technique described by Rögener as early as in 1952 /9/. Rögener obtained niobium nitride wire samples by nitrogen diffusion into niobium wire.

In the process as modified by us, niobium single crystal samples were nitrided. These samples were separated from a zone molten No single crystal rod with some $9 \mathrm{~mm}$ diameter. As a facility for sample nitriding we used an autoclave made by Degussa /20/. This allowed experiments to be conducted up to a maximum gas pressure of 100 bar. However, the heater of this system was a graphite resistance heating element: In this way, the test atmosphere always contained a certain amount of carbon, with the consequence that the specimens absorbed not only nitrogen but also a small fraction of carbon. This test facility is certainly able to raise the nitrogen fraction of carbonitrides. However, the heater was not suitable for the preparation of pure nitrides. 


\section{$\underline{2 . C}$}

As another possibility for nitriding No single crystals, as mentioned under item $B$ above, we had our single crystal drawing system with a RF-heater as described above, in which all further experiments were conducted. Heating by RF, avoids the disadvantage of a graphiteheater, but this $\mathrm{RF}$-furnace is outlined up to a maximum pressure of only 20 bar.

In a first series of experiments the niobium specimens were suspended from tungsten wires and directly heated by means of RF (Fig. 7).

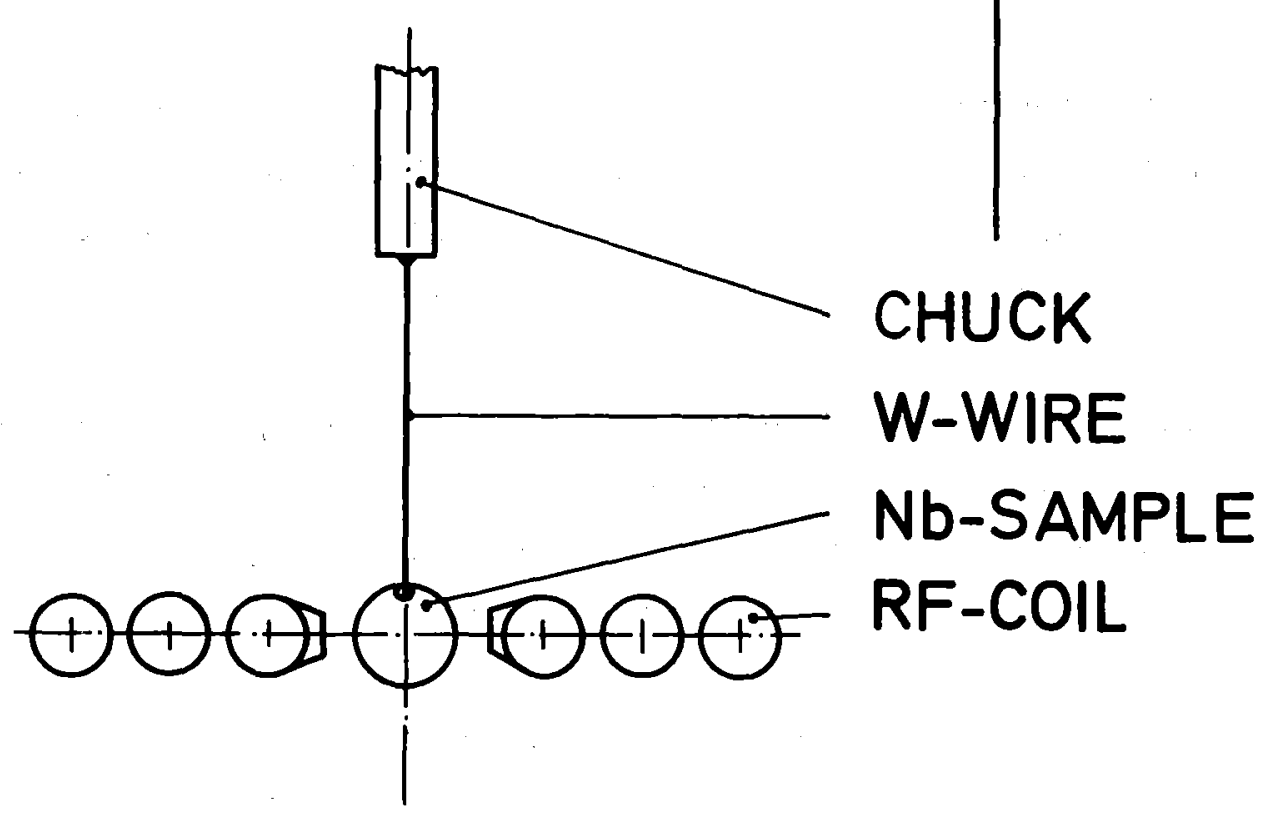

Fig. 7 Direct heating arrangement

The temperature was set between 1600 and $2000^{\circ} \mathrm{C}$ by means of a pyrometer and monitored for the duration of the experiment. The nitrogen used had a purity of $>99.9995$ vol. \&. A downstream oxisorb gas cleanup system was used to reduce further residual impurities of oxygen and water vapor. The pressure was 20 bar in all cases. 
Nitriding of the specimens was stopped by simple cut-off of the generator power after 114 to 434 hours. As a consequence, the specimens cooled very quickly because of the small sample size and the relatively high nitrogen pressure of 20 bar. This was to prevent conversion of the $\delta-\mathrm{NbN}$ high temperature phase into the $\gamma+\varepsilon-$ low temperature phases $/ 14 /$.

Some of the $\mathrm{Nb}-$ specimens were cut like small disks (diameter $9 \mathrm{~mm}$, thickness between 2 and $3 \mathrm{~mm}$ ), some of them were cylinders $9 \mathrm{~mm}$ in diameter and 10 to $15 \mathrm{mrn}$ long which were axially perforated to reduce the diffusion length.

At a given nitrogen pressure, according to the phase diagram, the nitrogen fraction that can be achieved in the material is - the higher, the lower the temperature setting is. However, a reduction of temperature inhibits the diffusion of $\mathrm{N}$ into $\mathrm{Nb}$, which greatly prolongs the duration of the experiment. Since even at a temperature of approx. $1800^{\circ} \mathrm{C}$ and a thickness of the specimen disk of only $3 \mathrm{~mm}$ nitriding had to be continued for several weeks to avoid a major nitrogen concentration gradient, lower temperatures than $1800^{\circ} \mathrm{C}$ would have necessitated intolerably long durations of the experiment.

Also enlargement of the dimensions of the specimen greatly prolongs the diffusion time. For this reason, care was taken to ensure that the diffusion length did not exceed $1.5 \mathrm{~mm}$ for all points of the specimen. Table 2 is a survey of the most important data of these experiments.

Since it turned out to be very costly to incur all the experimental expense and the relatively long experimental time for only one specimen at a time, direct coupling of RF to the specimen was excluded. We selected a crucible of tungsten metal heated by RF. This crucible was able to accomodate several niobium specimens of different sizes which could then be heated indirectly and nitrided at the same time. Fig. 8 shows the arrangement. The crucible material was tungsten, because it does not react with nitrogen up to very high temperatures $/ 21 /$. This arrangement at the same time has the advantage that both oxygen and water vapor residues of the gas and from the wall of the recipient, respectively, will react with the tungsten crucible above approx. $600^{\circ} \mathrm{C} / 21 /$ and in this way protect the niobium crystals contained in the crucible. 

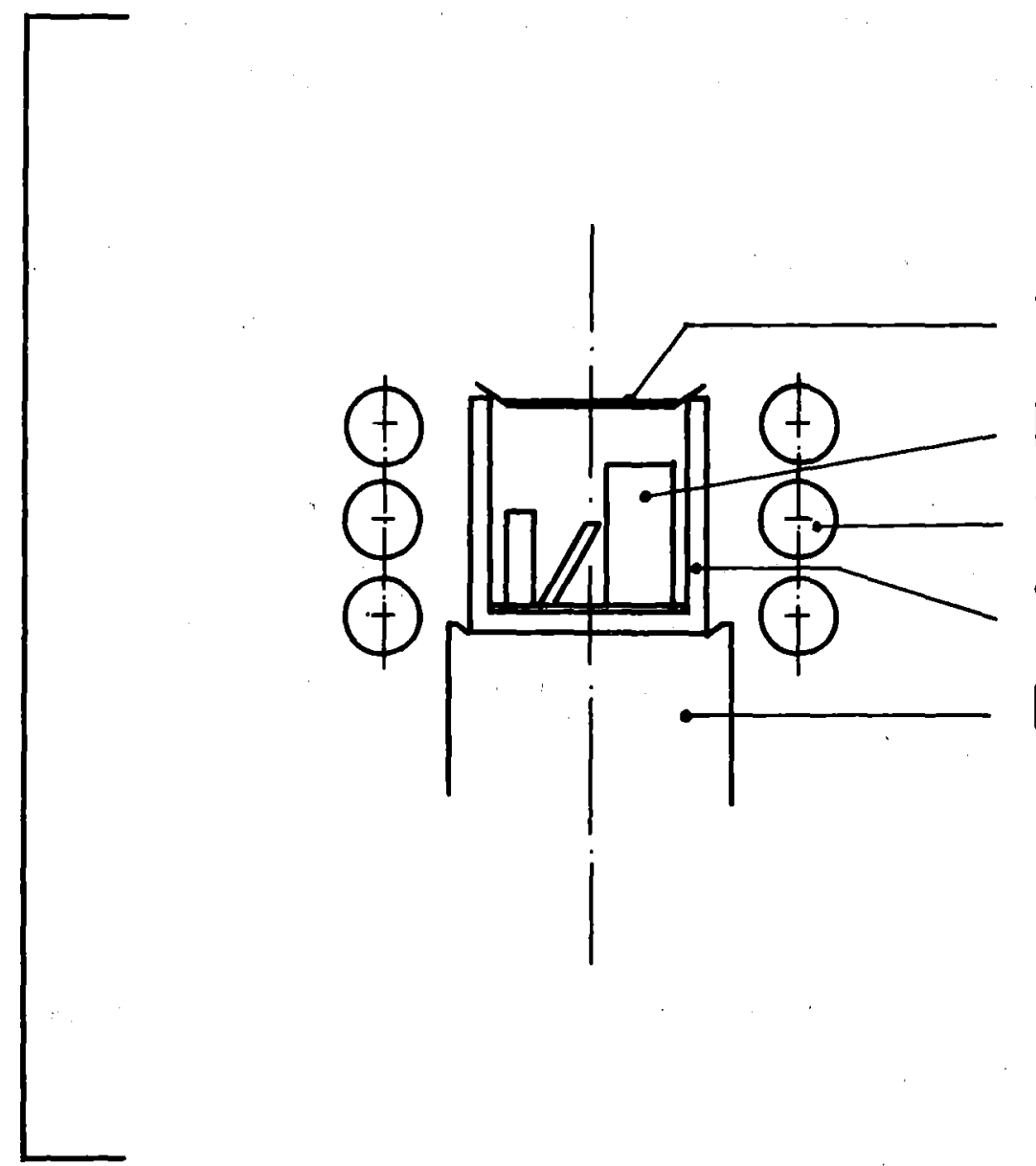

W-SHEET Nb-SAMPLES RF-COIL W-CRUCIBLE BN-SUPPORT

Fig. 8 Nitriding arrangement with w-crucible

\section{Characterization}

For the characterization of the specimens the distribution of lattice parameters was measured by neutron diffraction and the fraction of the different phases was determined accordingly. It was found that part of the single-crystals consisted of a mixture of $\gamma$ - and $\delta$-phases (tetragonal and cubic) with a $\gamma$-phase contribution of up to $40 \%$, whereas other specimens contained only the cubic $\delta$-phase.

The superconducting transition temperature of our specimens was measured by the induction-and partly by the resistance method. The measuring accuracy was approximately \pm 0.2 degrees. 
The chemical analysis with respect to the nitrogen was carried out by the vacuum hot extraction method. In the most adverse case it will work to an accuracy of $\pm 0.2 \mathrm{wt} . \%$ for an assumed bulk nitrogen fraction of $11 \mathrm{wt}$. \%

The specimens were examined quantitatively also for oxygen, carbon and partly for hydrogen. Table 3 shows a few representative data of some selected specimens.

In some specimens no chemical analysis was carried out because all the volume was needed for measuring purposes. In those cases it was possible to determine the lattice constant and the superconducting transition temperature from which the $\mathrm{N} / \mathrm{Nb}$ ratio could also be determined by means of data found in the literature /22/.

\section{Conclusion}

Within the limits of our equipment various methods were applied to prepare niobium nitride single crystals.

Zone melting of niobium nitride rods at pressures of up to 20 bar merely resulted in very low-nitrogen material of the composition of $\mathrm{NbN}$.64 in the range of $\gamma+\beta$-phases.

It was shown that nitriding niobium single crystals over a period of several days by direct or indirect heating, in a tungsten crubcible, to 1600 up to $2000^{\circ} \mathrm{C}$ under nitrogen pressures of 20 bar is a workable possibility to prepare $\delta-\mathrm{NbN}$ single crystals .

The composition was determined by chemical methods. Our best samples had a $N /$ Nb ratio of about 0.89 . A typical superconducting transition temperature was found to lie between 14.5 and $15 \mathrm{~K}$.

This method of fabrication can probably be applied also to prepare other transition metal nitrides. 


\section{Acknowledgement}

The author would like to express his special gratitude to Dr. H. Schneider, IMF, for having carried out the chemical analyses. Thanks are also due to Dr. W. Reichardt, IAK, for his support in structural examination by means of neutron scattering of the specimens prepared and for many helpful discussions and to $W$. Abel, IAK, for his support and advice in special computer programs. 


\section{References}

/1/ B. Scheerer, J. Fink, W. Reichardt, KFK 2139 (1975)

/2/ B. Scheerer, KFK-Report 2183, 89 (1975)

/3/ B. Scheerer, KFK-Report 2054, 74 (1974)

/4/ B. Scheerer, "Herstellung von Karbid Einkristallen, am Beispiel von TiC, NbC und VC", Tagung über Kristallwachstum u.-züchtung, Jülich, Sept. 1975

15/ L. Pintschovius, W. Reichardt und B. Scheerer, Verh. der DPG, April 1976, R.6,Bd 11 (1976) S.738

/6/ F. Gompf, L. Pintschovius, W. Reichardt and B. Scheerer, in Proc. Conf. on Neutron Scattering, Gatlinburg, p. 129-135 (1976)

/7/ L. Pintschovius, W. Reichardt and B. Scheerer,

J. Phys. C: Solid State Phys., Vol. 11, 1557-62 (1978)

/8/ G. Aschermann, E. Friedrich, E. Justi und J. Kramer, Phys. Z. 42,349 (1941)

/9/ H. Rögener, Z. Physik 132, 446 (1952)

/10/ G.V. Samsonov, O.I. Shulishova, I.A. Shcherbak, Poroshkovaya metallurgia, No. 12 (144), S. 76-78 (1974)

/11/ K. Hechler und E. Saur, z. Phys. 205, 392-99 (1967)

/12/ A.N. Christensen, DGKK-Tagung, Stuttgart, Sept. 1977

/13/ G. Braver, H. Kirner, Z. anorg. allg. Chemie, Bd. 328, 34 (1964)

/14/ R.W. Guard, J.W. Savage und D.G. Swathout, Transact. of the Met. Soc. of AIME 239, 643 (1976)

/15/ c. Politis, KFK-Ext. 6/78-1 (1978)

/16/ Leybold Heraeus, 6450 Hanau

/17/ Hüttinger-Elektronik, 78 Freiburg

/18/ Cerac Inc., Butler, Wisconsin, USA

/19/ P. Ettmayer, R. Kieffer und F. Hattinger, Metall 28, 1151 (1974)

/20/ Degussa Industrieofenbau, Wolfgang, Postfach 602, 6450 Hanau

/21/ Metallwerk Plansee AG., A-6600 Reutte

/22/ L.E. Toth, Academic Press, New York and London, Vol. 7, 94,221 (1971) 
TABLE 1 : Chem. analysis of some powder rods (wt. \&)

\begin{tabular}{l|r|c|c|c} 
Chem.No. & $\mathrm{N}$ & $\mathrm{N}$ & $\mathrm{C}$ & $\mathrm{H}$ \\
\hline $106 / 75$ & 9.4 & 1.06 & $\mathrm{n} . \mathrm{a}$. & $<0.01$ \\
$157 / 76$ & 10.0 & 1.63 & 0.36 & $\mathrm{n} . \mathrm{a}$. \\
$72 / 77$ & 10.4 & 1.85 & 0.59 & 0.02 \\
$161 / 77 / 1$ & 11.1 & 1.0 & 0.98 & $<0.01$ \\
$161 / 77 / 2$ & 11.2 & 0.95 & 0.74 & 0.02 \\
$161 / 77 / 3$ & 9.8 & 0.9 & 0.79 & $<0.01$ \\
$161 / 77 / 4$ & 11.2 & 0.84 & 0.39 & $<0.01$ \\
$161 / 77 / 5$ & 10.3 & 0.79 & 0.40 & $<0.01$ \\
$221 / 78$ & 10.4 & 2.1 & 0.02 & $\mathrm{n} . \mathrm{a}$.
\end{tabular}


TABLE 2 : Experimental data

\begin{tabular}{|c|c|c|c|c|c|c|c|}
\hline $\begin{array}{l}\operatorname{Exp} \cdot \\
\text { No } .\end{array}$ & $\begin{array}{l}\text { Start. } \\
\text { Mat. }\end{array}$ & $\begin{array}{l}\text { Dimens. } \\
\text { mm }\end{array}$ & $\begin{array}{l}\text { Temp. } \\
\text { OC }\end{array}$ & $\begin{array}{c}t \\
\text { hrs. }\end{array}$ & $\begin{array}{l}\mathrm{RF}-\mathrm{h} \\
\text { direct }\end{array}$ & $\begin{array}{l}\text { leating } \\
\text { |W-crucible }\end{array}$ & $\begin{array}{r}\mathrm{T}_{\mathrm{C}} \\
\mathrm{K}\end{array}$ \\
\hline 199 & $\mathrm{NbN}_{1-\mathrm{x}}$ & rod & molten & & zone $\mathrm{n}$ & melting & 6.6 \\
\hline 280 & $\mathrm{Nb}$ & $8 \times 1.5$ & 2000 & 140 & $\mathrm{x}$ & & 14.1 \\
\hline 283 & $\mathrm{Nb}$ & $8 \times 40$ & 2000 & 235 & $\mathbf{x}$ & & \\
\hline $284 a$ & $\mathrm{Nb}$ & $6 \times 2.0$ & 2000 & 140 & $\mathbf{x}$ & & \\
\hline $284 b$ & $\mathrm{Nb}$ & $6 \times 1.5$ & 1800 & 140 & $\mathrm{x}$ & & \\
\hline 285 & $\mathrm{NbN}_{1-\mathrm{x}}$ & $\mathrm{Nr} .283$ & 2000 & 114 & $\mathrm{x}$ & & 13.4 \\
\hline 287 & Nbo & $6 \times 2.5$ & 1850 & 115 & $\mathrm{x}$ & & \\
\hline 288 & $\mathrm{Nb}$ & $10 \times 4.0$ & $1600-2000$ & 164 & $\mathrm{x}$ & & \\
\hline 290 & $\mathrm{Nb}$ & $11 \times 2.5$ & $1700-2000$ & 215 & $x$ & & 13.2 \\
\hline 291 & $\mathrm{No}$ & $9 \times 3.5$ & 2000 & 142 & $\mathrm{x}$ & & 11.6 \\
\hline 293 & $\mathrm{Nb}$ & $9 \times 3.0$ & $1600-1900$ & 126 & $\mathrm{x}$ & & 14.0 \\
\hline 295 & $\mathrm{Nb}$ & $8 \times 15 . \S$ & 1900 & 240 & $\mathrm{x}$ & & \\
\hline 298 & No & $8 \times 13 . \S$ & 1900 & 240 & $x$ & & 11.9 \\
\hline 299 & $\mathrm{Nb}$ & $6 \times 2 \times 13$ & $1700-1900$ & 158 & & $x$ & 15.3 \\
\hline 300 & $\mathrm{Nb}$ & $7 \times 11 . \S$ & $1900-1700$ & 408 & & $x$ & 14.4 \\
\hline $300 a$ & $\mathrm{NbN}_{1-\mathrm{x}}$ & No . 199 & $1900-1700$ & 408 & & $x$ & 14.5 \\
\hline $300 \mathrm{~b}$ & $\mathrm{NbN}_{1-\mathrm{x}}$ & No .288 & $1900-1700$ & 408 & & $\mathrm{x}$ & 14.2 \\
\hline $300 \mathrm{c}$ & $\mathrm{NbN}_{1-\mathrm{x}}$ & No .298 & $1900-1700$ & 408 & & $\mathrm{x}$ & 15.2 \\
\hline 314 & $\mathrm{Nb}$ & $8 \times 13 . \S$ & 1700 & 434 & & $\mathrm{x}$ & 13.6 \\
\hline
\end{tabular}

$\S$ Cylinder with central hole $\varnothing 2 \mathrm{~mm}$ 
TABLE 3 : Chem.analysis of some crystals (wt. 8 )

\begin{tabular}{c|c|c|c|c|c|c} 
Chem.No. & Exp.No. & $\mathrm{N}$ & $\mathrm{O}$ & $\mathrm{C}$ & $\mathrm{H}$ & $\mathrm{N} / \mathrm{Nb}$ \\
\hline $9 / 76 \mathrm{a}$ & $199 / 1$ & 8.7 & 0.83 & 0.05 & $<0.02$ & 0.63 \\
$9 / 76 \mathrm{~b}$ & $199 / 2$ & 8.8 & 0.83 & 0.67 & $<0.02$ & 0.64 \\
$111 / 78 \mathrm{a}$ & 283 & 8.9 & 0.2 & $<0.005$ & $\mathrm{n} . \mathrm{a}$. & 0.64 \\
$111 / 78 \mathrm{~b}$ & 290 & 10.7 & 0.8 & 0.02 & & 0.794 \\
$111 / 78 \mathrm{c}$ & 291 & 9.2 & 0.47 & $<0.005$ & & 0.672 \\
$257 / 78$ & 298 & 10.6 & 0.7 & $<0.01$ & & 0.785 \\
$88 / 79$ & 300 & 11.8 & 0.21 & 0.013 & & 0.885 \\
$89 / 79$ & 314 & 11.3 & 0.2 & $<0.01$ & & 0.846
\end{tabular}

Exp.No. 199/1 : at start of zone-molten part

Exp.No. 199/2 : at end of zone-molten part 


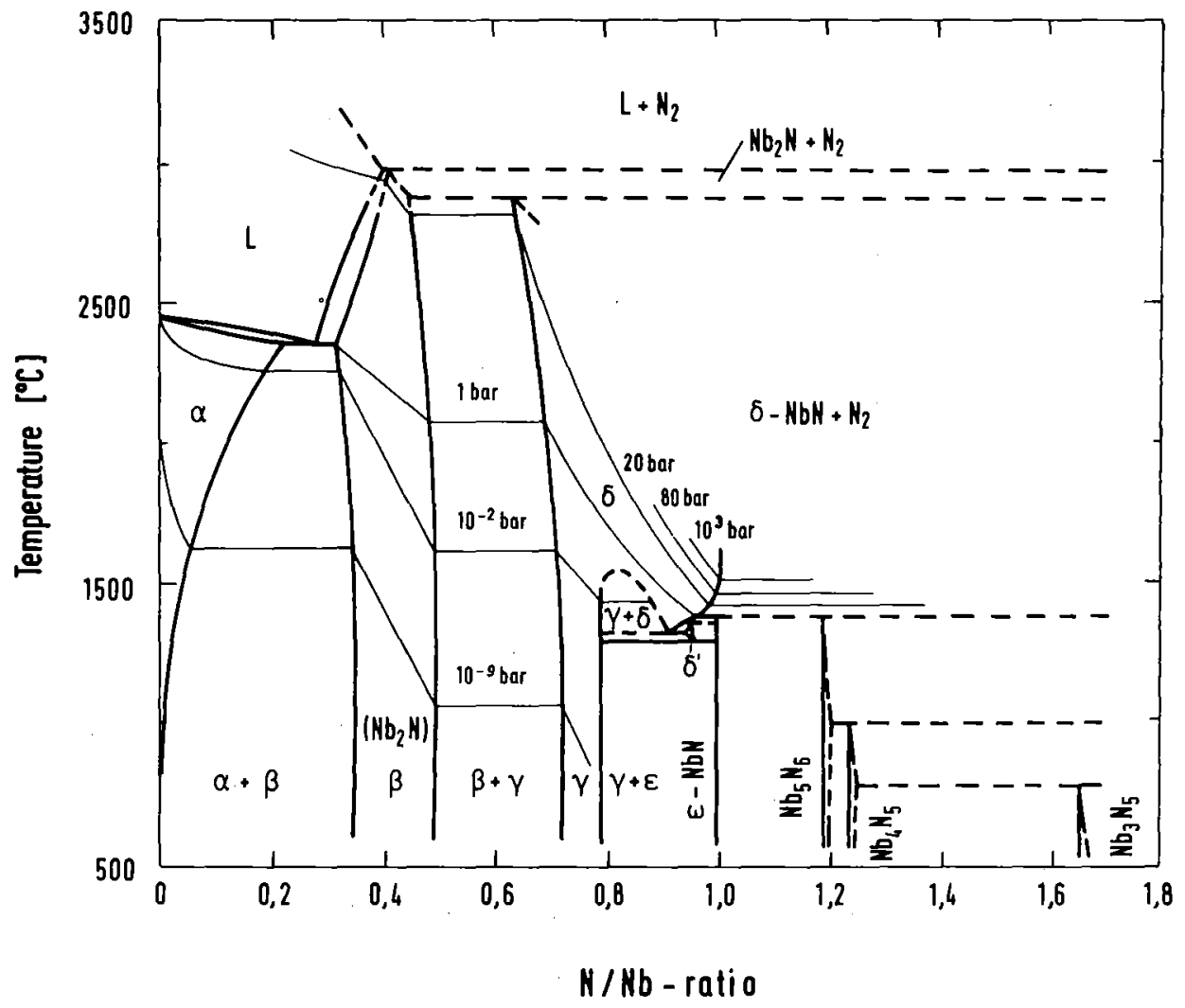

Proposed phase diagram for $\mathrm{Nb}-\mathrm{N} / 15 /$ 


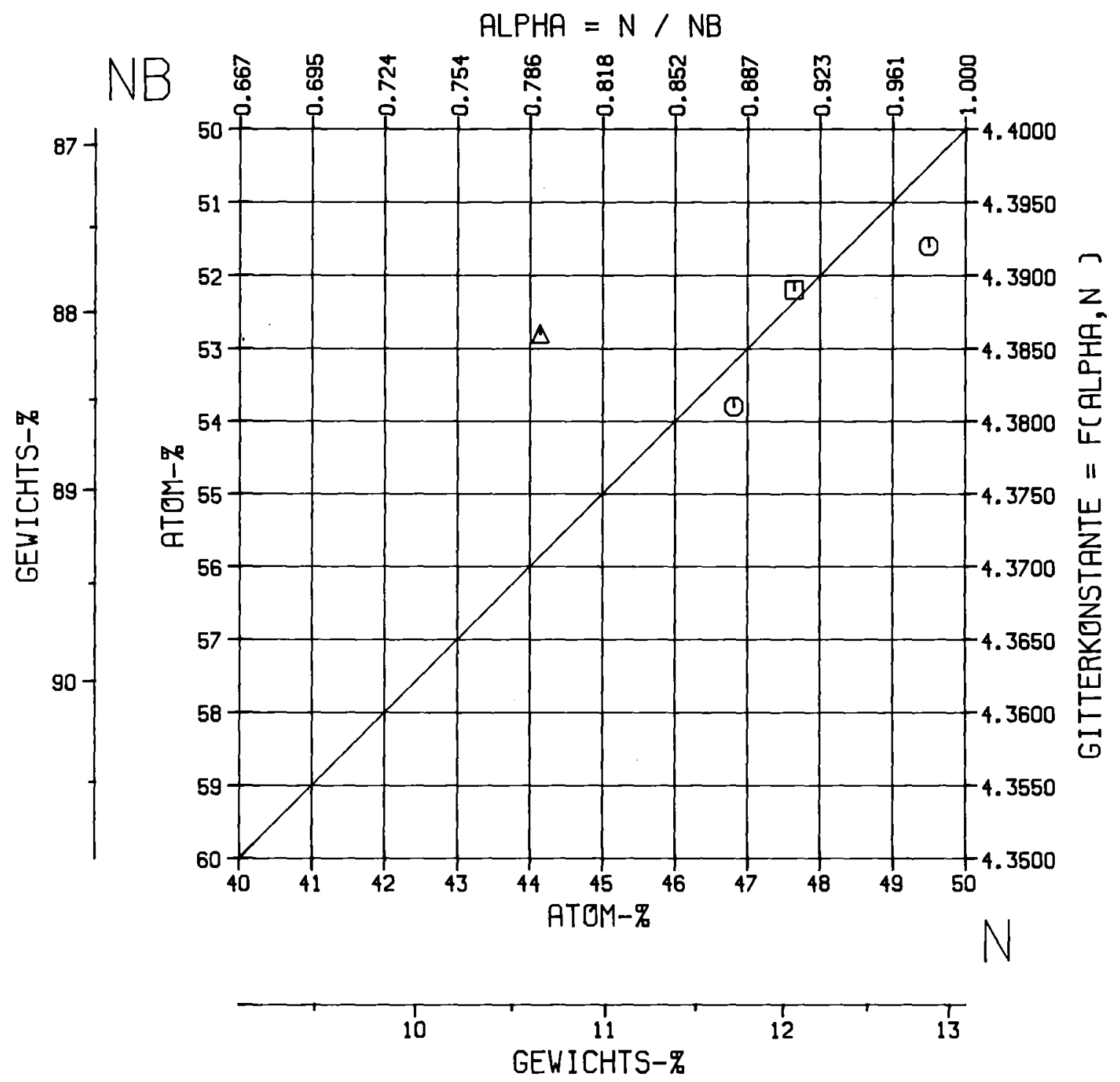

(1) KIEFFER R. ET.AL., METALL26, HEFT7, ( 1972)

(1) BRAUER, G. , +ESSELBORN, R. ,Z. ANGRG. CHEM. 309, 151-70, ( 1961-B)

$\triangle$ ZITAT WIE UBEN, NBN. 79=TETRAGONAL, $A=4.386, C=4.335$

Tab. 4 : Conversion table 